\title{
Efficient Way to Detect Bone Cancer using Image Segmentation
}

\author{
S. P. Anandaraj, N. Kirubakaran, S. Ramesh, J. Surendiran
}

\begin{abstract}
Malignant growth is a wild division of irregular cells, which is spread over the parts of the body. Bone disease is one of the sorts of malignancy. Bone malignancy is a pernicious and threatening illness, caused because of uncontrolled division of cells in the bone. The most compromising and usually happened malignancy is bone disease. Prior the location of bone malignant growth is most testing issue. A definitive objective of this paper is to play out an examination on the bone disease pictures to discover the tumor. In this exploration we are looking at $K$-implies and fluffy $C$-Means grouping procedures to recognize the presize accuracy tumor part in the bone. In this exploration at first picture experiences into the division procedure and $k$-implies and Fuzzy $C$-Means calculations are connected to distinguish the exact tumor part in the bone. In this exploration is completely utilized MATLAB as a programming instrument for the way toward stacking a picture and to perform picture division. For clear comprehension of this exploration the outline and the outcomes will be shown in the sessions of this paper Keywords: Tumor, $k$-means algorithm, image segmentation.
\end{abstract}

\section{INTRODUCTION}

This Disease can start wherever in the body. It starts when cells wind up insane and assemble out standard cells. This makes it troublesome for the body to work the manner in which it should. Tumor can be managed great for a few people. Honestly, a larger number of people than some other time in ongoing memory have full presences after tumor treatment. Threat isn't just a single disease. There are numerous sorts of ailment. It's not just one contamination. Threat can start in the lungs, the chest, the colon, or even in the blood. Illnesses are undefined here and there, yet they are differing in the manners in which they create and spread.

The cells in our bodies all have certain occupations to do. Customary cells disengage deliberately. They pass on when they are depleted or hurt, and new cells have their spot. Infection is the time when the cells start to end up wild. The tumor cells keep creating and making new cells. They swarm out customary cells. This causes issues in the bit of the body where the development started.

Development cells can in like manner spread to various parts of the body. For instance, threat cells in the lung

Revised Manuscript Received on 14 August, 2019.

Dr.S.P.Anandaraj, Professor,Department of Computer science and Engineering, Mallareddy Engineering College for Women anandsofttech@gmail.com

Dr.N.Kirubakaran, Professor, Department of Electronics and Professor,Department of Computer science and Engineering, Mallareddy Engineering College for Women iamkiru70@gmail.com

Dr.S. Ramesh, Professor, Department of Electronics and Professor,Department of Computer science and Engineering, Mallareddy Engineering College for Women itz_ramesh87@gmail.com

Dr.J.Surendiran, Professor, Department of Electronics and Communication Engineering' Jaya college of Engineering and Technology. surenjaya1981@gmail.com can go to the bones and create there. Exactly when harm cells spread, it's called metastasis (meh-TAS-tuh-sister). Exactly when lung development spreads to the bones, it's still called lung threat. To authorities, the development cells during the bones look basically like the ones from the lung. It's not called bone threat except if it started during the bones.

A couple of malignancies create and spread speedy. Others build up even more bit by bit. They furthermore respond to treatment in different ways. A couple of sorts of threat are best treated with medical procedure; others respond better to drugs called chemotherapy (key-mo-THER-uh-pee). Every now and again no less than 2 prescriptions are used to get the best results. When someone has tumor, the expert should find what kind of illness it is. People with harm require treatment that works for their kind of ailment.

\section{a. What is Bone Cancer?}

Bone disease begins in the bone. Malignancy begins when cells in the body start to become wild. Cells in almost any piece of the body can progress toward becoming tumor, and can spread to different zones of the body.

\section{b. Types of bone tumors:}

\section{$>$ Essential and optional bone tumor}

Essential bone malignancy begins in the cells of the bones. The tumor cells are bone cells that have turned out to be harmful. All the data in this segment is about essential bone growth. The vast majority who have tumor cells in their bones don't really have essential bone growth. They have disease cells that have spread into the bone from a growth somewhere else in the body. This is called auxiliary or metastatic bone disease. So for instance, in the event that you have bosom tumor that spreads to the bones, the malignancy cells in the bones will really be bosom disease cells.

\section{$>$ Osteosarcoma}

You can get osteosarcoma at any age. Be that as it may, it's the most well-known kind of essential bone disease found in adolescents and youthful grown-ups. Osteosarcomas can develop anyplace in the skeleton. The most widely recognized locales for osteosarcoma include:

around the knee

the lower thigh bone (femur)

the upper shin bone (tibia)

around the shoulder

the upper arm bone (humerus)

Published By:

Blue Eyes Intelligence Engineering \& Sciences Publication 


\section{Ewing's sarcoma}

Ewing's sarcoma is most basic in youngsters. It more often than not begins in the:

$$
\begin{aligned}
& \text { pelvis (hips) } \\
& \text { thigh (femur) } \\
& \text { shin (tibia) }
\end{aligned}
$$

You can get an Ewing's tumor in the delicate tissues of the body. Delicate connective tissue tumors are called delicate tissue sarcomas. These are dealt with an indistinguishable path from Ewing's bone tumors.

\section{Chondrosarcoma}

Chondrosarcoma is regularly found in grown-ups matured in the vicinity of 30 and 60 years of age. It is a malignancy of ligament cells inside the bone.

Ligament is the gleaming, smooth substance that typically covers the closures of bones in the joints. However, it can likewise be found inside the bone.

Chondrosarcoma can become inside a bone or on the bone surface. The most widely recognized locales for chondrosarcoma are the:

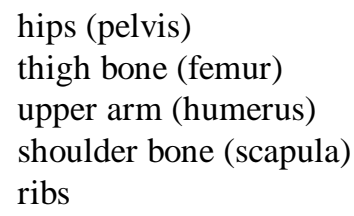

\section{Axle cell sarcoma}

Axle cell sarcomas are fundamentally the same as osteosarcomas however don't create the hard substance called osteoid, which osteosarcomas do. They carry on like osteosarcomas and specialists treat them comparatively. They are typically found in grown-ups more than 40 . There are a few sorts of axle cell sarcoma they are:

\section{- Undifferentiated sarcoma of bone}

This implies the cells are not particular. They are very undeveloped (youthful) and it isn't conceivable to tell which sort of ordinary bone cells they began from.

\section{- Harmful stringy histiocytoma (MFH)}

The greater part of the tumors that used to be called MFH are currently more precisely analyzed as different sorts of sarcoma. The modest number that would at present be called MFH are currently known as undifferentiated high review pleomorphic sarcoma. At the point when this tumor begins in the bone, your specialists may allude to it as shaft cell sarcoma of the bone.

\section{Fibrosarcoma}

This is exceptionally uncommon and regularly found in moderately aged grown-ups. The most well-known site for fibrosarcoma is the thigh bone (femur).

\section{- Leiomyosarcoma of bone}

This is to a great degree uncommon and little is thought about this kind of shaft cell sarcoma. Your master will talk you through what they think about having leiomyosarcoma of the bone.

\section{- Chordoma}

Chordomas are an extremely uncommon, moderate developing sort of bone disease.

Chordomas create from the notochord, which shapes the early spinal tissue in a child creating in the womb. After around a half year, this tissue is supplanted by bone. Be that as it may, now and then little zones of notochord may remain.

\section{RELATED WORK}

Around 2 out of 5 chordomas ( 35 to $40 \%$ ) develop in the skull or the bones amidst the face. The rest create in the bones of the spine.

Worldwide Childhood Cancer Day is commended yearly on 15 February to bring issues to light and to express help for youngsters and teenagers with malignancy, survivors and their families. Every year, more than 200,000 kids are determined to have malignancy - an ailment that touches innumerable families and groups in all areas of the world. With access to quality care, over $80 \%$ of kids with tumor can survive, living full and solid lives. In any case, numerous youngsters in low-pay and center salary nations don't get or finish mind, and, accordingly, more than $90 \%$ of youth tumor passings happen in low asset settings.

World Cancer Day, sorted out by the Union for International Cancer Control (UICC) and praised every year on 4 February, is a chance to rally the worldwide group to end the treachery of preventable experiencing tumor. The topic of World Cancer Day 2017 is "We can, I can" and features the requirement for multisectoral cooperation. WHO has given direction on the best way to address the tumor trouble through exhaustive disease control, established on worldwide coordination and solid wellbeing frameworks. The Organization has helped lead engagement of accomplice UN offices and elements, for example, the UN Joint Global Program on Cervical Cancer Prevention and Control. Coordinated effort is basic to create a more grounded reaction against this ailment that unnecessarily kills millions around the globe every year.

\section{EXPERIMENTAL METHODOLOGY}

a. K-means algorithm:

Clustering is a procedure of clustering objects into incoherent clusters so the data in a similar cluster are comprative, however data having a place with various cluster vary. A cluster is an accumulation of data question that are like each other are in same cluster and not at all like the objects are in other clusters. The interest for sorting out the sharp expanding data what's more, 
taking in significant data from data, which makes clustering strategies are generally connected in numerous application territories, for example, manmade brainpower, science, client relationship administration, data pressure, data mining, data recovery, picture preparing, machine learning, promoting, medication, design acknowledgment, brain research, insights et cetera. Group examination is an instrument that is utilized to watch the qualities of group and to concentrate on a specific cluster for promote examination. Clustering is unsupervised learning and don't depend on predefined classes. In clustering we measure the uniqueness between objects by measuring the distance between each pair of objects.

\section{K-Means clustering algorithm}

1) Consider data set of $n$ objects. Let $X=x 1, x 2, x 3$,., $x n$ be the set of data points and $\mathrm{V}=\mathrm{v} 1, \mathrm{v} 2$,, $\mathrm{vc}$ be the set of centres.

2) Consider K fixed centre points. Randomly select cluster centres.

3) Take each point belonging to data set and associate it to the nearest centre till no point is left alone. Then form $\mathrm{K}$ groups.

4) Calculate the distance between each data point and cluster centres.

5) Assign the data point to the cluster centre whose distance from the cluster centre is minimum clusters.

6) At this point we need to relocate K new centroids.

7) Recalculate the new cluster centre using

$$
V_{i}=\left(1 / C_{i}\right) \sum_{j=1}^{C_{i}} X_{i}
$$

Where $\mathrm{Ci}$ represents the number of data points in ith cluster.

8) After we have K new centroids, a new binding has to be done between the same data set points and the nearest new centres.

9) A loop has been generated, as a result of this loop we may notice that the $\mathrm{K}$ centres change their location step by step until no more changes are done.

10) If no

$$
J(V)=\sum_{i=1}^{C} \sum_{j=1}^{C}\left\|X_{i}-V_{j}\right\|^{2}
$$

were reassigned then stop the process otherwise repeat from step 5.

Note: In K-Means the number of centres is fixed apriorily.

\section{b. Fuzzy C-Means algorithm:}

Fuzzy C-Means is one of the efficient clustering techniques to avoid the noise in the data. This method is invented by Dunn in 1973 and investigated by Bezdek in 1981. In this algorithm each data point is assigned with membership corresponding to each cluster centre on the basis of distance between the data point and the cluster centre. Formation of clusters can be done by grouping the data points with corresponding cluster centres. Each data point is assigned to each cluster centre on the basis of the factor distance. In this minimum distance is considered to group the data points with cluster centre. Where the distance is minimum between the centre and data point, that data point is grouped with that cluster centre. In this algorithm the data point may be belongs to one or more clusters but differentiation will be done by the percentage of the membership of data point with particular cluster centre. But finally summation of all the membership data points should be equal to one. After each iteration the cluster centres are updated by using the formula:

$$
\begin{aligned}
T_{i j} & =\left(\frac{1}{\sum_{k=1}^{c}\left(\frac{\mathrm{d} i j}{\mathrm{~d} j k}\right)^{\frac{2}{m-1}}}\right) \\
V_{j} & =\left(\frac{\sum_{i=1}^{n}\left(T_{i j}\right)^{m} X_{i}}{\sum_{i=1}^{n}\left(T_{i j}\right)^{m}}\right)
\end{aligned}
$$

where

$$
\begin{gathered}
n \rightarrow \text { is number of data points } \\
V \rightarrow \text { jth cluster centre } \\
m \rightarrow \text { Fuzziness index } \\
c \rightarrow \text { number of cluster centers }
\end{gathered}
$$

$T \rightarrow$ Membership of ith data to jth cluster center

$d \rightarrow$ Euclidean distance between ith and jth cluster centre

\section{FUZZY C-MEANS Clustering algorithm:}

1) Consider data set of $n$ objects. Let $X=x 1, x 2, x 3, ., x n$ be the set of data points and $\mathrm{V}=\mathrm{v} 1, \mathrm{v} 2, \mathrm{vc}$ be the set of centres.

2) Select cluster centre.

3) Calculate the fuzzy membership Tij by using the formula:

$$
T_{i j}=\left(\frac{1}{\sum_{k=1}^{c}\left(\frac{\mathrm{d} i j}{\mathrm{~d} j k}\right)^{\frac{2}{m-1}}}\right)
$$

where

$$
\begin{aligned}
& d_{i j}=\left\|X_{i}-C_{j}\right\| \\
& d_{i j}=\left\|X_{i}-C_{k}\right\|
\end{aligned}
$$

4) Compute the updated fuzzy centers $\mathrm{Vj}$ using the formula:

$$
V_{j}=\left(\frac{\sum_{i=1}^{n}\left(T_{i j}\right)^{m} X_{i}}{\sum_{i=1}^{n}\left(T_{i j}\right)^{m}}\right)
$$

5) Repeat the step 2 and 3 until achieving the minimum $J$ value and update the $\mathrm{U}(\mathrm{k}), \mathrm{U}(\mathrm{k}+1)$. Where $\mathrm{U}$ is a fuzzy membership matrix.

Fuzzy C-Means is one of the efficient clustering techniques to perform segmentation on an input image. In this process segmentation is performed by means of various color factors because color posses wavelength values of an image. Similar wavelength values of an image are grouped 
into different clusters. Here we are using MATLAB 2013a to perform clustering on an image.

Now let us observe the results of both K-means and Fuzzy C-Means algorithms:

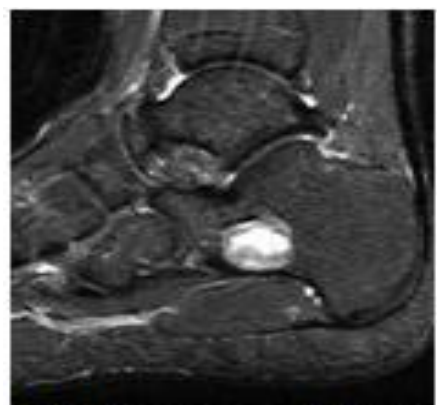

MRI image of foot

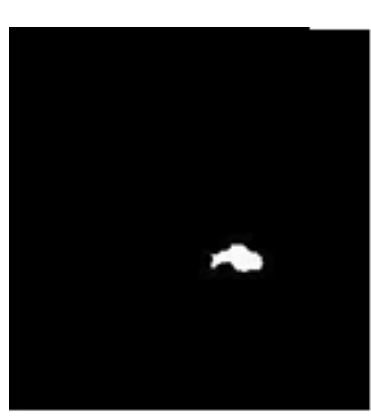

Fuzzy C-Means image

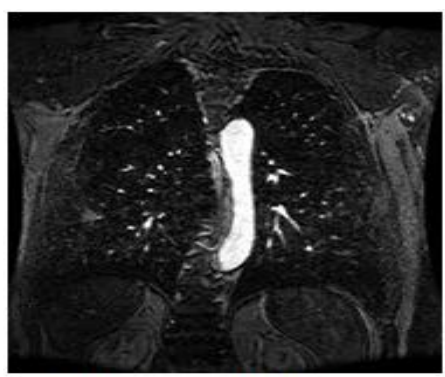

MRI image of Lung

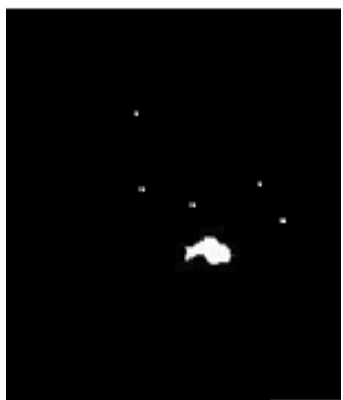

K-Means clustred image

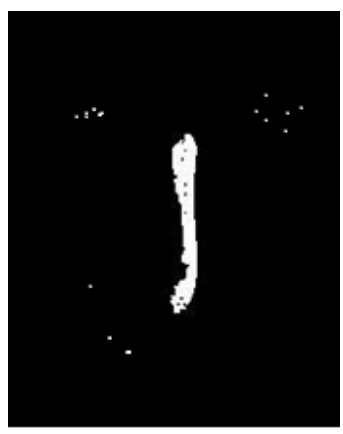

K-Means Clustered image

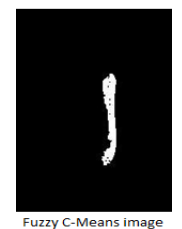

\section{CONCLUSION}

In this paper we talked about information mining grouping procedures and picture division. The primary objective of this paper is to discover the precise piece of tumor in bone which prompts bone malignant growth. In this we examined about picture division and K-Means and Fuzzy C-implies calculations to play out the grouping on bone picture to discover the tumor. By contrasting both the outcomes we can demonstrate that Fuzzy C-Means calculation giving more precise outcomes than K-Means calculation.

\section{REFERENCES}

1. Pabitra Roy and Sudipta Roy, “An Automated Method for Detection of Brain Abnormalities and Tumor from MRI Images", International Journal of Advanced Research in Computer Science and Software Engineering,2013,pp.1528-1589.

2. Rohit S. Kabade and M. S. Gaikwad "Segmentation of Brain Tumour and Its Area Calculation in Brain MR Images using K-Mean Clustering and Fuzzy C-Mean Algorithm", International Journal of Computer Science \& EngineeringTechnology,2013,pp.524-531.

3. Dr.S.P.Anandaraj " Research Opportunities and Challenges of a Security Concerns associated with Big Data in Cloud Computing", IEEE International conference on ISMAC IoT in Social, Mobile, Analytics and Cloud published in IEEE Explore, DOI: 10.1109/I-SMAC.2017.8058278, Electronic ISBN: 978-1-5090-3243-3,Print ISBN: 978-1-5090-3242-6, INSPEC Accession Number: 17224835 on 10th to 11th Feb, 2017.

4. Ramesh, S 'An Efficient Secure Routing for Intermittently Connected Mobile Networks', 2017, Wireless Personal Communications, ISSN 0929-6212 Vol.94, No.4, pp. 2705 - 2718

5. Ankita Singh, Dr Prerna Mahajan, "Comparison Of K- Means And Fuzzy C- Means Algorithms" International Journal of Engineering Research \& Technology (IJERT), Vol. 2 Issue 5, May 2013.

6. R.Suganya, R.Shanthi," Fuzzy C- Means Algorithm- A Review" International Journal of Scientific and Research Publications, Volume 2 Issue 11, November 2012.

7. Adele P. Peskin and Karen Kafadar, "Robust Volume Calculations Of Tumors Of Various Sizes" Scientific Application and Visualization Group National Institute of Standards and Technology, Boulder, Colorado 80305 USA.

8. Kirubakaran, N. and Kathirvel, A. "A Unified Approach for detecting and eliminating selfish nodes in MANETS using TBUT", Springer-EURASIP Journalof on Wireless and Communications and Networking, Vol.143 DOI: 10.1186/s13638-015-0370x, 2015.

9. Dr.S.P.Anandaraj, S.Poornima, Sougandhika Reddy,M Sindhuja,P.Vedhakshatha, "Semantic Analysis On Communication And Security Issues Of Extensible Authentication Protocol (EAP) On Wireless Networks" International Journal of Advanced Computing and Electronics Technology(IJACET), ISSN(P):2394-3408,(O):2394-3416,Vol 2, No 1, January 2015

10. Soumi Ghosh, Sanjay Kumar Dubey "Comparative Analysis of K-Means and Fuzzy C-Means Algorithms", International Journal of Advanced Computer Science and Applications, Vol. 4, No.4, 2013.

11. Madhuri Avula, Narasimha Prasad Lakkakula, Murali Prasad Raja, "Bone Cancer Detection from MRI Scan Imagery Using Mean Pixel Intensity" IEEE 2017

12. C. Kishor Kumar Reddy, P.R. Anisha, G.V.S. Raju, "A Novel Approach for Detecting the Tumor Size and Bone Cancer Stage Using Region Growing Algorithm" IEEE journal.

13. Ramesh, S \& Ganesh Kumar, P , 'Spray and wait routing with agents in intermittently connected MANETs', 2013, Journal of Artificia Intelligence, ISSN 1994-5450, vol. 6, no. 2, pp. 123-133

14. Kirubakaran, N. and Kathirvel, A. "Performance Improvement of Security Attack in Wireless Mobile Ad Hoc Networks", Research Journal of Asian Journal of Information Technology, Vol.13, No.2, pp. 68-76, 2014.

15. Krupali D. Mistry,Bijal J. Talati, "Integrated approach for bone tumor detection from MRI scan imagery" IEEE journal

16. Tanuja K. Sarode, Bhavik Thakkar, Sanket Purandare, Vikas Gupta, "Cancerous cell detection in bone marrow smear using Haar Image Transform”, IEEE journal 2017.

17. Dr.S.P.Anandaraj, D.Naveen Kumar, S.Poornima, "Invariant Character View Recognition in Artificial Neural Networks based on pattern classification" Global Journal of Computer Science and Information Technology (GJCSIT), Vol 1, No.1,pp. 33-37, Oct 2014.

18. Kirubakaran, N. and Kathirvel, A. "Secured Unicast Routing using Cross layer design in Wireless Mobile Ad Hoc Networks", The internationa journal of Forensic Computer Science , DOI: 10.5769/J201701002, 2017.

19. Ramesh, S \& Ganesh Kumar, P, 'A secure 3-way routing protocols for intermittently connected mobile ad hoc networks', The Scientific World Journal, ISSN: 1537-744X, July 2014, vol. 2014, Article ID. 865071 , pp. 1-13, DOI: $10.1155 / 2014 / 865071$.

20. Alan Jose, S.Ravi and M.Sambath . Brain Tumor Segmentation Using K-Means Clustering And Fuzzy C-Means Algorithms And Its Area Calculation, International Journal of Innovative Research in Computer and Communication Engineering, Vol. 2, Issue 3, March 2014.3496-350.

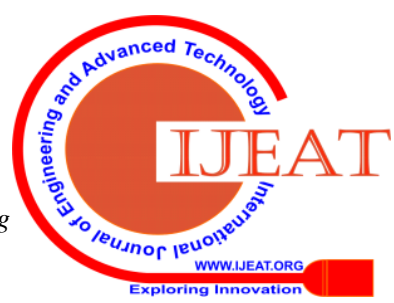


21. Sami Bourouis, Ines Chennoufi, Kamel Hamrouni, "Multimodal Bone Cancer Detection Using Fuzzy Classification and Variational Model", springer.

22. Nisthula P, Mr. Yadhu.R.B, “A Novel method to detect bone cancer using image fusion and edge detection", International Journal Of Engineering And Computer Science ISSN:2319-7242 Volume 2 Issue 6 June, 2013 Page No. 2012-2018.

23. N. Nithiyanandam, K. Venkatesh, M. Rajesh, Transfer The Levels Of The Monitored Carbon, Nitrogen Gases From The Industries, International Journal of Recent Technology and Engineering, Volume-7 Issue-6S3 April, 2019.

24. Sivanesh Kumar, A., Brittoraj, S., Rajesh, M., Implementation of RFID with internet of things, Journal of Recent Technology and Engineering, Volume-7 Issue-6S3 April, 2019.

25. Rajesh, M., Sairam, R., Big data and health care system using mlearningJournal of Recent Technology and Engineering, Volume-7 Issue-6S3 April, 2019.

26. Rajesh, M., and J. M. Gnanasekar. "Path Observation Based Physical Routing Protocol for Wireless Ad Hoc Networks." Wireless Personal Communications 97.1 (2017): 1267-1289. 